\title{
Environmental performance of social housing in emerging economies: life cycle assessment of conventional and alternative construction methods in the Philippines
}

\author{
Corinna Salzer $^{1} \cdot$ Holger Wallbaum $^{1} \cdot$ York Ostermeyer $^{1} \cdot$ Jun Kono $^{1}$
}

Received: 2 February 2016 / Accepted: 20 June 2017 /Published online: 17 July 2017

(C) The Author(s) 2017. This article is an open access publication

\begin{abstract}
Purpose The environmental impact of the social building stock is relevant, particularly in emerging economies. Life cycle thinking is not yet established, however. Locally available, alternative building concepts could potentially reduce the environmental impact of the construction segment. This paper examines the environmental performance of "as-built" low-cost housing for an example of the Philippines, and the potential to reduce its environmental impact through use of three alternative building technologies: cement-bamboo frames, soil-cement blocks, and coconut board-based housing.

Methods Life cycle assessment models are implemented and evaluated with software SimaPro, using the single-impact indicators global warming potential (GWP) and cumulative energy demand (CED) and the multi-impact indicator Impact2002+. According to EN 15978, the life cycle phase product and construction process (A), use stage (B), end-of-life (C) and supplementary information beyond the building life cycle (D) have been assessed. Theoretically calculated inflows from standard construction procedures used in phase A have been verified with 3 years of empirical data from implemented construction projects. For phases B, C and D, attention was given to service life, use-phase, allocation of waste products, biogenic carbon and land-use assumptions. Scenarios reflect the actual situation
\end{abstract}

Responsible editor: Trakarn Prapaspongsa

Electronic supplementary material The online version of this article (doi:10.1007/s11367-017-1362-3) contains supplementary material, which is available to authorized users.

Corinna Salzer

salzer@chalmers.se

1 Chalmers University of Technology, Gothenburg, Sweden in the emerging economy. Processes, such as heat recovery from thermal utilization, which are not existing nor near to implementation, were excluded.

Results and discussion For an assessment of the phases A-BC-D with GWP, a 35\% reduction of environmental impact for soil-cement blocks, $74 \%$ for cement-bamboo frame, and $83 \%$ for coconut board-based houses is obtained relative to a concrete reference house. In absolute terms, this relates to a reduction of 4.4, 9.3, and $10.3 \mathrm{t} \mathrm{CO}_{2}$ equivalents over a service life of 25 years. CED showed higher impacts for the biogenic construction methods coconut board and cement-bamboo frames of +8.0 and $+4.7 \%$, while the soil-cement technology was evaluated $-7.1 \%$ compared to GWP. Sixteen of 17 midpoint categories of Impact2002+ confirmed an overall reduction potential of the alternative building methods, with the midpoint category land occupation being the exception rating the conventional practice over the alternatives.

Conclusions It is concluded that the alternative construction technologies have substantial potential to reduce the environmental burden caused by the social housing sector. The service life of the alternative technologies plays a vital role for it. LCA for emerging economies needs to incorporate realistic scenarios applicable at their current state or belonging to the most probable alternatives to ensure valuable results. Recommendations for further research are provided.

Keywords Bamboo - Coconut - Climate change mitigation . Life cycle assessment $\cdot$ Philippines $\cdot$ Social housing $\cdot$ Soil cement $\cdot$ Sustainable building

\section{Introduction}

The construction sector ranks among the most energy-intensive, resource-depleting and emission-releasing industries 
globally (UNEP SBCI 2009; Ortiz et al. 2009). Over more than two decades, a pressing need for more sustainable urban housing at a global scale has been highlighted (Rasoolimanesh et al. 2011; SDSN 2013). This has created incentives for formal material and construction providers to change their products and practices, and environmental concerns have received great attention with respect to buildings (Frischknecht et al. 2015). However, the built environment of low-income groups or the so-called semi-formal or informal construction sector and its environmental performance has often been disregarded. Given its relevance as a rapidly growing part of the construction industry in emerging economies, this paper contributes to the discussion. Although the percentage of people living in informal settlements in the Asia Pacific region is decreasing, their absolute numbers continue to increase, underlining that poverty and disparity are characteristics of the "urban century", with more than half of the population living in cities. According to the United Nations, approximately $40 \%$ of urban residents live in inadequate housing in the Asia Pacific region (UN-ESCAP and UN-Habitat 2011). Here, adequacy refers to shortcomings of structural quality, land rights, access to basic services and healthy living environments. There is a tremendous, continuously increasing global housing backlog of cost-efficient, resilient housing (CIB 2014). In the Philippines, a housing backlog of 6 million exists (NSO 2013; NHA 2015). The Philippines experience rapid urban growth, poverty increase, strong vulnerability of low-income groups to disasters and visible effects of climate change. These factors continuously exacerbate the housing backlog, which is why it has been chosen as pilot country for this paper.

The present work raises the question as to how the challenge of sustainable and resilient housing for lowincome groups can be tackled in an inclusive way. Great potential, in the Philippines and elsewhere, is seen for the use of locally available, underutilized alternative construction materials in more cost-efficient, disasterresilient and socially inclusive houses (UN Habitat 2012). In Salzer et al. (2016), a holistic, multiperspective development is suggested for alternative construction materials, along the sustainability dimensions economy, ecology, and society as well as technology, capturing the technical requirements of building concepts, and governance, adding the requirements of local regulations. In tropical climates, such as the Philippines, round bamboo is such a raw material, with an intriguing potential (Paudel and Lobovikov 2003). Being abundantly available, fast growing and culturally anchored in society, as well as having properties and ability to be engineered into performing building concepts, round bamboo is a viable material for housing (Barile 2007; Base Builds 2015). The use of round bamboo embedded in advanced building concepts, compared to laminated bamboo, does further not require investment into industrial processing facilities, allows decentralized supply and employment in locations, where social impact creation is most needed, and matches with local skills levels. Soil-cement blocks, another raw material, are produced from locally available soils and engineered over decades to withstand earthquakes. Additionally they have properties that naturally balance indoor climates (Habitech 2015). The raw material coconut husk, a waste stream of 16 billion coconuts produced annually in the Philippines, is suitable for pressing into coconut boards for cladding of frame-based houses (Keijsers et al. 2006; Philippine Coconut Authority 2012; Boeger et al 2017). With the potential of replacing wood-based boards in a country with massive deforestation, this technology is a third major alternative for the Philippine market.

The general objective of the paper was to identify the environmental impact of low-rise residential concrete buildings on the low-income sector in the Philippines relative to three identified alternative construction technologies, namely, cement-bamboo frames, soil-cement blocks and coconut board-based houses through life cycle assessment (LCA). This paper focuses on the performance of selected environmental indicators. The results will feed into the holistic sustainability assessment covering the dimensions economy, ecology, society, governance and technology (Salzer et al. 2016). LCA studies for the building sector have been summarized in several scientific reviews, such as Khasreen et al. (2009), Ortiz et al. (2009), Singh et al. (2011), Cabeza et al. (2014) and Abd Rashid and Yusoff (2015). Although established, the varying scopes and boundaries of different LCA results have recently led to a call for harmonization of LCA for buildings (Frischknecht et al. 2015). The LCA concept is used in the Asia Pacific region, but is not as widespread as in western countries (Abd Rashid et al. 2013). Globally, LCA studies tackle mostly "exemplary" buildings, not ordinary building stock (Cabeza et al. 2014). Khasreen et al. (2009) identified the need to apply LCA to buildings in developing countries as a key area of future research. The present work contributes to the discussion, by introducing LCA in the context of a rapidly growing informal construction sector of an emerging economy.

Subsequent to the introduction, Sect. 1 of this paper, Sect. 2 provides a description of the LCA methodology, scope and boundaries of the assessment. Key results are documented in Sect. 3, giving evidence for a substantial reduction of negative environmental impacts of the alternative materials relative to conventional practices. In the discussion, conclusion and recommendations of Sects. 4 and 5, the results are comprehensively discussed, and their contribution to the environmental impacts of the informal construction sector are highlighted. 


\section{Methodology}

This section is organized into two parts. In the first part, the concept, process and elements of LCA are described. In the second, the material and energy flows of life cycle inventories (LCIs) are addressed.

\subsection{Life cycle assessment}

LCA is an established method for assessing the environmental performance of products and services, and it is therefore commonly used to evaluate buildings and their materials (Finkbeiner et al. 2014). The present work followed the terminology and declaration of life cycle phases of EN15978, in which the standard for assessing the environmental performance of buildings is defined (EN15978 2011). This research is also in compliance with the general principles for LCA of ISO14044 and contains the elements: goal definition and scope, inventory analysis and impact assessment and interpretation (Rebitzer et al. 2004; Finkbeiner et al. 2006; ISO International Organization for Standardization 2006). We use the terminology of EN15978. For the assessment, we used software SimaPro and the database ecoinvent v2.2 (Althaus et al. 2010; ecoinvent Centre 2014; PRé Consultants 2015). In the Impact Assessment, two of 25 recommended indicators of EN15978, global warming potential (GWP) and cumulative energy demand (CED), are displayed to enable a focused results and discussion section. To evaluate the robustness of the trends obtained with use of the two single-impact indicators, a multi-impact indicator allocated to four endpoint damage categories was applied, containing several more single-impact indicators named in EN15978.

\subsubsection{Goal definition and scoping}

The scope of the present LCA is to compare the environmental performance of a conventional concrete block house to others built with construction methods using bamboo, soil-cement and coconut husk panels. The three alternative construction methods were identified because of the raw material availability of round bamboo, lime-soil and coconuts in the Philippines, the existence of technical innovations using these raw materials in advanced building concepts fabricated by local skills and predicted construction costs at par or at lower cost per square meter than the conventional concrete block house (Base Builds 2015). As functional equivalent (FE) built-up, square meters per service life was considered, which is in line with previous publications on LCAs for buildings (Ortiz et al. 2009; Cabeza et al. 2014; Abd Rashid and Yusoff 2015) and facilitates comparability. We analysed a standard one-story unit with a $25-\mathrm{m}^{2}$ floor plan and a total net wall area of 54.4- $\mathrm{m}^{2}$ excluding door and window openings, as displayed in Fig. 1. The building envelop reflects a common size and layout often found in the Philippine social housing sector (Base Builds 2015; NHA 2015). We assumed that all houses, irrespective of their building technology, have a service life of 25 years. The decision to limit the service life of conventional concrete houses to 25 years, despite the technologies' theoretical potential to sustain longer, was driven by factors found in the context of social housing and the tropics. Main arguments were the high exposure to risks and aggressive climate owing to location of social housing in the tropics, a high uncertainty in the quality of execution and social dynamics in the market segment social housing, where inhabitants strive to transition into next higher societal segments. For detailed reasoning regarding this service life, refer to the discussion in Sect. 2.2.5.

\subsubsection{Inventory analysis}

The section names all identified mass and energy flows throughout the lifespan of the FE. In line with the definition in EN15978 2011, phases A1-A5 cover cradle-to-completion of construction works. The latter contains the levels (A1-A3) with material supply, transport from source to factory and production and (A4-A5) with transport from factory to site and actual house construction. Phases B, C and D cover the occupation, end-of-life stages and scenarios beyond the building life cycle. Initially, theoretically modelled datasets for phases A1-A5 were produced through foreground data from
Fig. 1 Visualization of the building envelope: one-story $\mathrm{FE}$ house, $25 \mathrm{~m}^{2}$, 25-year service life
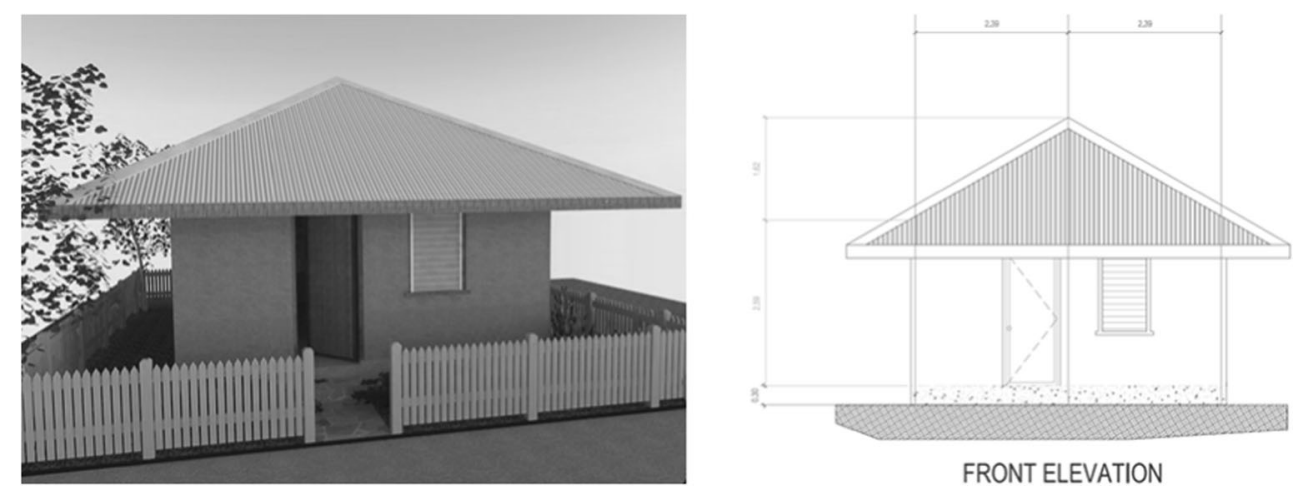
expert interviews with local and international forestry and soil-cement block experts, who provided inflow data for pre-chains of bamboo, coconut and soil-cement. Local characteristics were included such as harvesting, yield, transport and processing for the selected species and production and construction processes for stabilized soil blocks. For annually published data, 2013 was chosen as the reference year. Theoretically modelled data were triangulated using application data. Empirical inventories, documented through bill of materials, were collected over a period of 3 years from the Homeless People's Federation of the Philippines (2013) for the two block-based construction technologies, and Base Builds (2015) for the bamboo building envelopes. The consistency of the bill of materials was checked through correlation with lists of consumed materials after construction. Any possible deviations were discussed with the builders and where applicable used to refine the dataset applied in this paper. This ensured that the inventories reflect actual houses in the Philippines. The coconut husk panel technology was not at the stage of actual implementation and is therefore only modelled theoretically.

To show the difference caused by a change of technology for the building envelope, similar elements across the houses, such as windows, electrical, plumbing and the reinforced concrete foundation, were excluded from the assessment. For finishing elements, such as windows, all the technologies permit the integration of various standards, depending on client wishes. Therefore, the choice of building envelope per se does not cause a change in finishing. For foundations, the bio-based houses have only one third the dead weight of block-based technologies. In theory, this enables the reduction of foundation dimensions. The latter remains, however, a theoretical saving potential and not a current practice, so it was therefore excluded because of the following reasons. Codes are not adjusted to lightweight residential houses and become legal barriers to reduction. A system change in common foundation practices needs capacity building for both workers and clients of houses to understand the implementation not as a quality reduction. Moreover, case-specific technical assessments must ensure consideration of extreme suction forces by typhoons and land conditions often not ideal for social housing projects. The approach of exclusion is in line with EN 15804:2012+A1:2013 (2015), wherein processes or procedures shall not be included that are not in current use. Only the context-specific, probable and practical potentials to reduce environmental impact by the choice of the building material are captured in absolute numbers.

Because of the absence of empirical data for LCI phases B, $\mathrm{C}$ and $\mathrm{D}$, scientific assumptions were captured in scenarios. For the use phase (phases B1-B5), these include the service life of the houses, energy consumption during the phase and frequency of maintenance and repair interventions. Phase replacement and refurbishment were not considered, given the lifespan of only 25 years. For end-of-life (phase C) and impacts beyond the boundary conditions (phase D), we examined scenarios for demolition and recovery, including biogenic carbon considerations and the allocation of impact to waste products. Results of phases B-D were considered to have greater uncertainty, because their implementation is far in the future and rarely empirically studied. Although this already holds true for LCA assessments in a western context, data shortage in emerging economies and the informal sector of housing are more severe. Figure 2 summarizes the coverage of the considered LCA phases.

We used the ecoinvent database as described in Althaus et al. (2010) and ecoinvent Centre (2014). In the absence of regional data in the aforementioned database for Southeast Asia, the sensitive background processes "transportation", "energy" and "steel" were developed for the countryspecific context of the Philippines to ensure that major regional characteristics were captured. For further details, it is referred to in the Electronic Supplementary Material.

\subsubsection{Impact assessment}

For the assessment of buildings, 25 indicators are recommended by EN15978 (2011). In the present research, the analysis focuses on the visualization of two single-impact indicators from among these 25: First, cumulative energy demand (CED), which provides a scientifically acknowledged good general indication of LCA results (Huijbregts et al. 2010); second, global warming potential (GWP) from the International Panel for Climate Change (IPCC), which is a frequently used single impact indicator to retrieve numbers for $\mathrm{CO}_{2}$ savings (IPCC 2014). In addition, we considered the evaluation method Impact2002+, developed at the Swiss Federal Institute of Technology of Lausanne (Jolliet et al. 2003). It evaluates the impact of a product or service through 17 midpoint categories, allocated to the four-endpoint damage categories Human Health, Ecosystem Quality, Climate Change and Resources. The indicator contains the midpoint impact categories GWP and non-renewable energy in its categories Climate Change and Resources, but covers several more midpoint impact categories mentioned by EN15978, allocated to four endpoint damage categories. The endpoint category Ecosystem Quality contains among others acidification of soil and water and eutrophication. It also considers land occupation, a relevant midpoint category for biogenic materials. The endpoint damage category Human Health contains ozone layer depletion and ionizing radiation. The latter is not yet part of EN15978, but is intended for consideration in the next revision of the standard. Resource use contains mineral extraction relevant for mineral building materials as well as non-renewable energy. For this paper, Impact2002+ is displayed in its aggregated endpoint categories. Relevant sensitivities on midpoint level are evaluated and highlighted. For more details on the indicator mid- and endpoints, it is referred to in the Electronic Supplementary Material. 


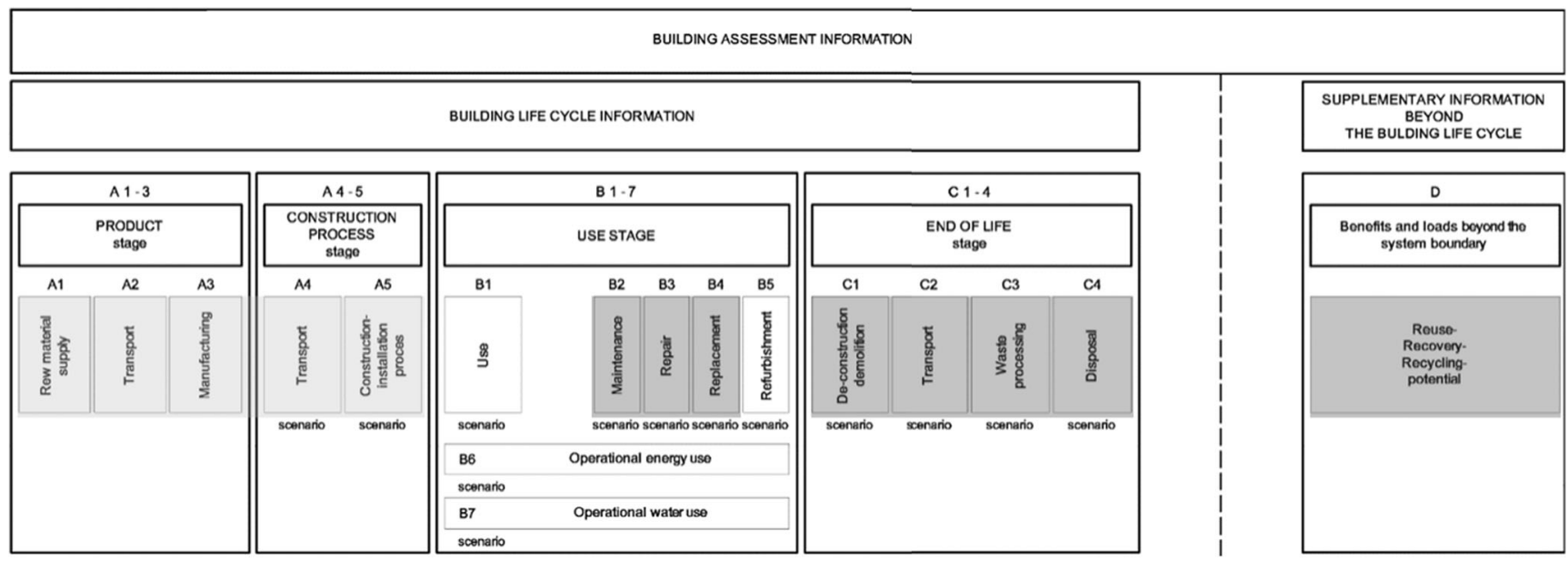

Fig. 2 Life cycle phases according to EN 15978: light grey represents theoretically modelled and empirically validated LCIs, and dark grey represents scenarios

\subsection{Data input to inventory analysis}

In the following, we describe input data for the LCIs, which include all considered material and energy flows throughout life cycle phases A1-A5, B2-4, C1-4 and D as well as why phases B1, B6 and B7 were excluded from the assessment. Inflow models of the building technologies concrete, cementbamboo frames, coconut board-based houses and soil-cement blocks are introduced with their A1-A5 phases. Subsequently, scenarios for phases B2-4, C1-4 and D are presented.

\subsubsection{Phases A1-A5 for conventional concrete reference house}

The most common construction technologies in the Philippines are either the reinforced concrete column and beam system (RCC) with filling by concrete hollow blocks (CHBs) or the load-bearing CHB masonry. The latter is more frequent in formal construction, whereas RCC frames are more often found in the informal sector. For both, construction is regulated in ASEP (2010). Structures, whether built by formal or informal providers, are often under significant price pressure. Simplifications outside accepted structural rules reduce cost but threaten structural performance. Postdisaster damage studies following a 7.1 Richter-scale earthquake in Bohol, Philippines in October 2013 documented deviations from the rules and their devastating effects under extreme impacts ASEP (2014). This is relevant for the LCA models because of two characteristics: (a) service life of buildings in a country with high frequency of extreme impacts can be significantly reduced, and (b) material inefficiencies must be adjusted to non-engineered building processes using bill-of-material data from actual projects. The present research distinguishes two characteristic construction types. The first is in compliance with structural rules, and the second is commonly built by labourers for the average-to-low wage earner in the country. We analysed the low-cost building sector in the Philippines to provide a realistic assessment of the environmental performance attained through a change of building practice. Therefore, we decided to compare the "as-built" version of conventional concrete houses with the aforementioned alternative building technologies. This captures the currently applied, most probable building practice with less efficient processes, higher share of manual activities and not optimized material wastage. This is in line with EN 15804:2012+A1:2013 (2015), in which it is recommended against the inclusion of processes or procedures not in current use such as an optimized building process or material consumption. High material inefficiencies, documented during construction practices, have been included as an allocation of wastage.

A1-A5 To create the modules concrete, Philippines, and concrete hollow blocks, Philippines, LCIs in the ecoinvent database were adjusted with the Philippine energy and transport module. For concrete, a standard mixture of $190 \mathrm{~kg}$ tap water, $1890 \mathrm{~kg}$ aggregates and $300 \mathrm{~kg}$ cement per $\mathrm{m}^{3}\left(2380 \mathrm{~kg} / \mathrm{m}^{3}\right)$ was considered (ecoinvent Centre 2014). Three main inflows were cement, CHB and steel. Cement was used for the RCC frame, CHB filling, block stacking, block cavity filling and plastering from inside and outside. Steel was an inflow as reinforcement steel, the roof substructure fabricated from CPurlins and C-Rafters as well as steel roof decking. A summary of the material LCIs for the conventional concrete hollow block construction is found in the Electronic Supplementary Material, the flowchart can be seen in Fig. 3.

\subsubsection{Phases A1-A5 for cement-bamboo frame house}

Bamboo is a building material with a long history in Asia and specifically the Philippines. With increasing pressure on resources, governments have incentivised the use of this rapidly 

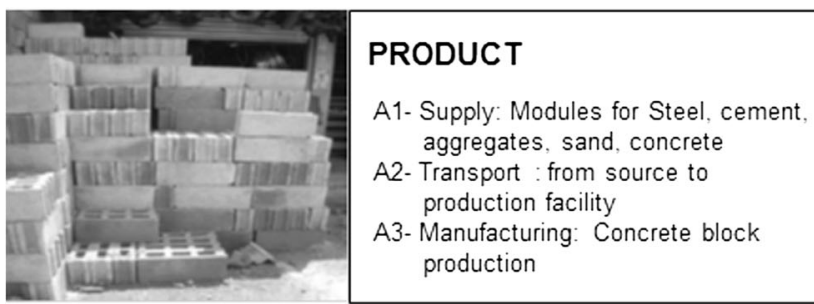

A1- Supply: Modules for Steel, cement, aggregates, sand, concrete

A2- Transport : from source to production facility

A3- Manufacturing: Concrete block production

\section{CONSTRUCTION PROCESS}

A4-Transport: From factory to construction site

A5- Construction: Construction works with RCC and $\mathrm{CHB}$, roof construction, finishing

Fig. 3 Flowchart of product-and-construction-process-stage (A1-A5) for social house made from reinforced concrete frame and hollow block filling

growing, available raw material (Department of Trade and Industry Philippines 2013). Traditional applications are often temporary and non-load bearing, such as fencing, windows, simple rural accommodations or room partitions in informal city settlements. Therefore, bamboo as a construction material has potential to be engineered, modernized and transferred to urban contexts in the country. A concept for prefabricated low-rise houses with a socially accepted design and approval per local building regulations has been introduced by Base Builds (2015) and is considered in this work.

A1-A5 Material and energy input data were based on the empirical bill of materials of $\sim 150$ bamboo-based houses constructed by Base Builds (2015). The latter is aggregated and documented in the Electronic Supplementary Material. The local bamboo species Bambusa blumeana was considered, because it has proven mechanical properties for application as structural members of houses (Salzer et al. 2017). The dimension of one bamboo culm varies according to its natural tolerance, from 8 to $11 \mathrm{~cm}$. A typical usable length of $6.00 \mathrm{~m}$ has been identified, which is usually harvested after 3-6 years (FPRDI 2002). All culms are harvested from natural stands, with average distance $20 \mathrm{~km}$ from farm to production facility. The rapid growth of bamboo ensures no depletion of stands when harvesting rates are limited to annual reproduction rates (International Network for Bamboo and Rattan 2011). The implemented LCI model for bamboo, at natural stand, has therefore the similar assumption of resource conservation as timber, at plantation in ecoinvent LCIs. Treatment needed to assure long-term insect resistance was modelled with the most common boron-borax acid solution, a natural water-based method and an alternative chemical product, as specified in the Electronic Supplementary Material. The latter is currently applied by Base Builds (2015) was used as base case. Figure 4 summarizes the process in a flowchart.
Owing to economic, social and technical optimizations in the period 2012-2014, different bamboo-based construction methods were assessed and applied over time. For more details on three bamboo-based building concepts covered through LCA, it is referred to the Electronic Supplementary Material. The cement-bamboo frame system was selected for the comparison in this paper. It uses round bamboo as a loadbearing structure and metal flat bars as bracing. An expanded metal mesh is used as a plaster carrier with $5-\mathrm{cm}$ mortar finish. Connections of bracing and round bamboo are filled with additional mortar. It is conservative for the LCA compared to other bamboo-based systems assessed, and is currently used in the Philippines by Base Builds (2015) due to its consistent technical performance in line with local building requirements against earthquakes, typhoons and fire, match with skill levels, ease of installation and high social acceptance.

Ten sensitivity analyses were performed on the A1-A5 level: (1) Bamboo yield per hectare; (2) bamboo sources natural stands or plantations (see also Sect. 4.1); (3) chemicals for insect treatment; (4) transportation distances according to empirical conditions; (5) degree of mechanization of processes; (6) prefabrication efficiency; (7/8) wastage in production and utilization of waste streams; (9) construction efficiency; and (10) updated bill of materials according to empirical as-built plans and technical optimizations. Exact configurations of the scenarios are in the Electronic Supplementary Material of this article. All sensitivities were grouped into scenarios of minimum and maximum environmental contribution per building technology.

\subsubsection{Phases A1-A5 for coconut board-based house}

At the centre of this construction technology are boards made from hot-pressed coconut husks. Intensive research on the coconut boards as a building material was done by

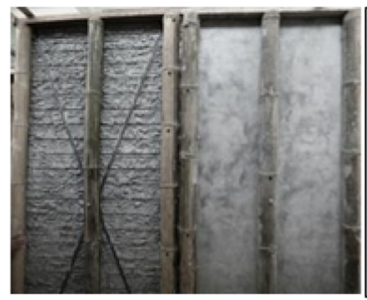

\section{PRODUCT}

A1- Supply: Harvesting of bamboo at plantation, drying and treatment A2-Transport: From farm to warehouse A3-Manufacturing: Pre-processing of bamboo, pre-fabrication of bamboo wall element

\section{CONSTRUCTION PROCESS}

A4- Transport: From factory to construction site

A5- Construction: Construction works from installation of prefabricated wall elements, cladding of walls, roof construction, finishing

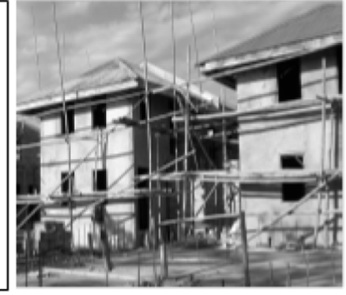

Fig. 4 Flowchart product-and-construction-process-stage (A1-A5) for cement-bamboo frame house (Base Builds 2015) 
Boeger et al. (2017), Snijder et al. (2005), Keijsers (2006), TenHave et al. (2010) and the Philippine Coconut Authority (2012). The husks are typically considered a waste product. The coconut industry is one of the most important business sectors in the Philippines, whose primary products are coconut copra and shells. Coconut husks are a widely available resource in the Philippines. Annually, 16 million coconuts produce half a kilogramme of waste husk each (Philippine Coconut Authority 2012). Using this waste, stream creates local value and a connection to the local tradition of coconut growing. The inflows for growing and harvesting used ecoinvent LCIs from the ecoinvent report (Zah and Hischier 2004). When pressing and heating milled husks, the natural lignin melts and forms a natural binder, replacing chemical adhesives. The absence of chemical products in coconut board production stimulates both environmental and social benefits. Findings of technical research show that the boards have good mechanical properties, and equipment for processing them and the energy intake for production is greater than that of gluebonded, pressed timber boards. For the LCA, we assumed that the coconut boards act as alternative cladding for loadbearing bamboo frame type 3, as described in Sect. 2.2.4. The flowchart in Fig. 5 summarizes the supply, production and construction steps of the coconut board-based house.

Four sensitivity analyses were done on the A1-A5 levels for this technology: (1) Land-use allocation to a waste product; (2) transportation distances; (3) energy demand; and (4) type of energy used. The exact configurations of the scenarios are in the Electronic Supplementary Material. All sensitivities were grouped into scenarios of minimum and maximum environmental contribution per building technology.

Use of the coconut husk material raises the question of allocation, because it was considered a waste product without contribution to land use and further inflows in the base case scenario. Allocation is recognized as a major contributor to changes in LCA results and has been identified as a gap in need of future research (Finkbeiner et al. 2014; Sandin et al. 2014). The coconut husk was modelled in economic scenarios with 0,5 and $10 \%$ contributions to the inflows of coconut production. It was decided to have a zero allocation in the base case, because the annual production volume of coconuts in the Philippines in the oil sector reaches 16 billion. Unlike the coconut shell, which is deemed a by-product because of its high calorific value, the husk is considered a waste product. Today, only $20 \%$ of coconut husks are used for low-cost products like rope and mattress filling. Eighty percent, associated with 8 million tons of husk, directly reach their end-of-life (EoL) rotting on coconut farms. Production of coconut husk-based panels could consume $10 \%$ of available husks. Even with an industrial-scale plant, maximum availability of the resource is far from being reached. Therefore, the designation as a pure waste product is considered appropriate.

\subsubsection{Phases A1-A5 for the interlocking soil-cement block house}

Interlocking soil-cement blocks are an established nonconventional technology. Comprehensive technical development in the Philippines has been undertaken by institutions such as the Asian Institute of Technology at regional level and the Homeless People's Federation of the Philippines (2013) at national level. Three decades of construction application has proven market acceptance (Habitech 2015).

A1-A5 At its core, the technology reduces mortar because of interlocking, cement-stabilized soil blocks. The ratio of cement for stabilization is relevant and varies according to soil quality, from 10 to $30 \%$. For the base case, a cement contribution of $20 \%$ was considered. Because no horizontal mortar is applied for stocking of the blocks, the inflow of cement is reduced. The blocks are reinforced in the horizontal and vertical directions. Empirical bill-of-material data from the Homeless People's Federation of the Philippines (2013) were used. Inventory phases at the A1-A5 levels of the soil-cement house are summarized below in Fig. 6.

Three sensitivity analyses were done at the A1-A5 levels for soil-cement block houses: (1) cement content; (2) degree of automation in production; and (3) reject rate of blocks. Exact configurations of the scenarios are in the Electronic Supplementary Material. All sensitivities were grouped into scenarios of minimum and maximum environmental contributions per building technology.

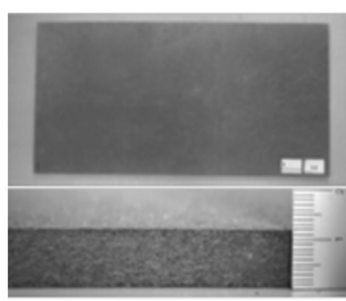

\section{PRODUCT}

A1-Supply: Collection of waste husk from farms

A2- Transport: From farm to collection point from there to Processing Facility

A3- Manufacturing: Pre-processing of husk, milling and conditioning, hot pressing into panels assembly into prefabricated wall elements

\section{CONSTRUCTION PROCESS}

A4- Transport: From facility to construction site

A5- Construction works: Installation of prefabricated wall elements, cladding of exterior walls, roof construction, finishing

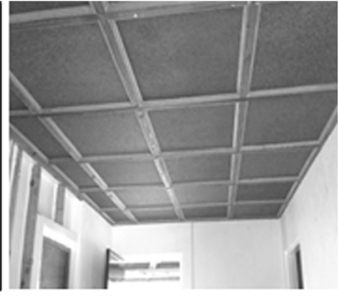

Fig. 5 Flowchart product-and-construction-process-stage (A1-A5) for coconut board-based house to be applied in the Philippines (Boeger et al 2017) 

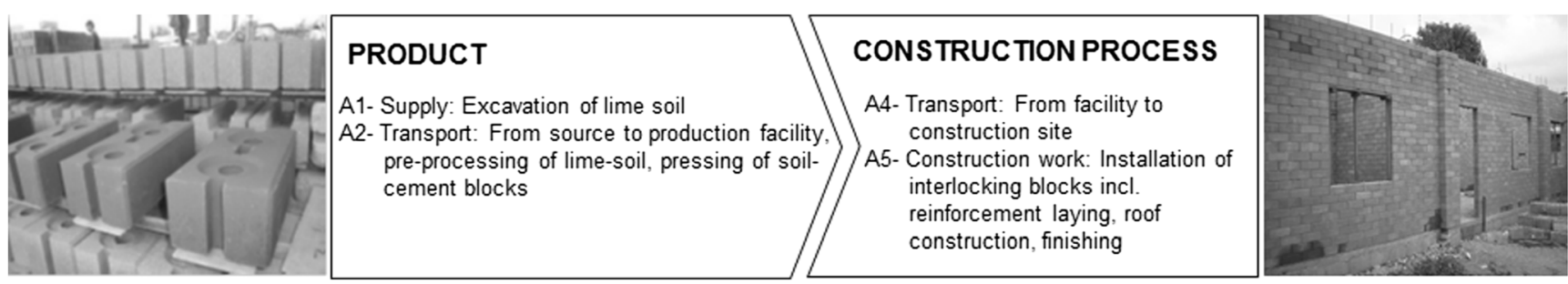

Fig. 6 Flowchart product-and-construction-process-stage (A1-A5) for soil-cement block house (Homeless People's Federation of the Philippines 2013)

\subsubsection{Phase B: use phase of the houses}

LCAs are more often used in exemplary projects with building-integrated technical systems, not for ordinary building stock (Cabeza et al. 2014). Multiple studies for exemplary houses state that energy consumption during the use phase (phase B6) of the house contributes 70-90\% to the overall life cycle balance (Ortiz et al. 2009; Cabeza et al. 2014; Abd Rashid and Yusoff 2015). Through advanced modelling of the use phase of buildings, it was shown that for more energy-efficient buildings, phases A1-A5 gain importance and the use-phase contribution decreases (Heeren and Hellweg 2014). Nevertheless, phase B remains the major contributor to the overall impact. This holds true for the industrialized building sector, but little is known about the use phase of naturally ventilated, low-cost houses. It is predicted that a building's use phase will not have the same importance over its life cycle. Factors for consideration are as follows: (1) service life of structures; (2) impacts of tropical climate (Abd Rashid and Yusoff 2015); (3) variations of user behaviour, unrelated to the design of the building envelope; and (4) strongly reduced technical building systems for low-cost houses. Below are the boundary conditions summarized for modelling phase $\mathrm{B}$ of social housing in the tropics.

- Phase B1: Emissions captured during phase B1 have been rarely documented in either well-studied exemplary projects or for social housing. This phase is therefore excluded from the assessment and should be studied for future inclusion.

- Phases B2-B5: These phases are little studied, which increases uncertainty in the inventory data. Efforts for maintenance (B2), repair (B3) and replacement (B4) interventions and their frequency have been distinguished. In the base case, phase B was applied every 6 years, if not a new construction was allocated in the said year. Refurbishment (B5) was excluded as unlikely in the informal context. Typical efforts for the conventional technology were identified through surveys of low-income groups (see the Electronic Supplementary Material) in combination with theoretical assumptions for the alternative technologies. Maintenance inflows were largely related to conventional, exterior parts of houses, and to alternatively built structures. The replacement of galvanized iron roof sheets and repair or maintenance of the facade was comparable for all house models. Inclusion of the phases was therefore of little relevance for comparative assessments between building technologies.

- Phases B6-B7: Energy use in the tropics is mostly determined by the cooling load. The latter depends on the building material, design of the building envelope, surrounding environment and exposure to heat intake. Small volumetric houses with metal roofing and without insulation, as analysed in our study, have substantial heat intake during the day. Higher thermal mass of structures causes higher nighttime temperatures within them. Construction costs of conventional solutions offer fewer opportunities for climate-adjusted design of the building envelope. Air conditioning is mostly unaffordable for the studied low-income settlements, albeit socially attractive. The effect of increased indoor comfort in phases B6 and B7 has yet to be quantified and understood in detail, and was therefore omitted in the assessment.

- Service life: Occupation of the houses was critically determined by the service life of the building technologies, which defined phase $\mathrm{B}$. The following base case and scenarios were considered to reflect this relevance.

- A 25-year lifespan for all technologies in the base case (lifespan $=$ reference study period or RSP), irrespective of their building technology. The most common time horizon of building LCAs consider 50 years as the service life (Ortiz et al. 2009; Cabeza et al. 2014; Abd Rashid and Yusoff 2015). These LCAs focus mostly on houses with advanced technical building systems in the formal building sector. The assumption is supported by empirical evidence of existing building stock. In the present work, the lifespan definition was not a pure technical consideration but reflected characteristics of building stock in the informal building sector. These characteristics include rapid transitions in societal status for low-income levels in Asian cities, hot-humid climates, a general trend toward substandard buildings quality at the base of the pyramid, and high frequency of extreme impacts, which can cause earlier failure of substandard structures. A service life of 25 years was therefore considered appropriate for structures in the informal sector, including concrete ones. The raw materials bamboo, coconut and soil are often used in a traditional, temporary manner in the Philippines, with a 
service life shorter than 5 years. For this work, only building technologies with comprehensive technical testing were compared, leading to selected, engineered building methods suited to the urban housing context. In other parts of the world, such advanced technologies with bamboo and soil-cement have a proven track record, reaching lifespans longer than 100 years (Cleuren and Henkemans 2003). Thus, a lifespan of 25 years for the alternative construction technologies was again considered appropriate.

- A lifespan of 10 years for alternative technologies, and 25 years for the conventional building method (factor 2.5 for all inflows of alternative methods at phases A, C and D, at same RSP).

- A lifespan of 10 years for the organic-based technologies, and 40 years for the conventional and soil-cement block building methods (factor 2.5 for organic materials, and factor 0.625 for block technologies at same RSP).

\subsubsection{Phases C and D: end-of-life and beyond life cycle scenarios}

Although EoL scenarios for the formal construction sector are often disregarded and have greater uncertainties (Abd Rashid and Yusoff 2015), some research has been done (Coelho and de Brito 2012; Carpenter et al. 2013; Sandin et al. 2014). It was found that phase $\mathrm{C}$ has $4-10 \%$ relevance in the overall LCA impact. Special attention was given to the distinction between phases $\mathrm{C}$ and $\mathrm{D}$. Phase $\mathrm{C}$ concludes when an endof-waste stage of outputs is reached. In this, the output must fulfil a specific purpose according to technical and legal requirements without causing any adverse impacts, and there is a demand for that output. Commonly distinguished are the demolition method and extraction rate $(\mathrm{C} 1)$, transportation means and fuel for the residuals (C2), waste processing (C3) and disposal methods (C4). Module D identifies components for reuse, recycling and energy recovery, and quantifies their respective net environmental benefits or loads outside the system boundaries of the given product (EN15978 2011). The scenarios for phases $\mathrm{C}$ and $\mathrm{D}$ were adjusted for the context of informal and low-cost construction. They focused on the main waste streams or resources, which were biogenic materials, concrete and steel. For the low-income building stock, the demolition of structures $(\mathrm{C} 1)$ is often done by a manual workforce instead of power tools or heavy machinery. A typical approach is documented in Fig. 7. This reduces the environmental impact of the demolition, although the overall effect of energy consumption for demolition is assessed to be relatively small. However, manual demolition implies lower recovery rates.

Poverty increases the direct and nearby reuse of organic raw materials and metal recycling, which is incentivised

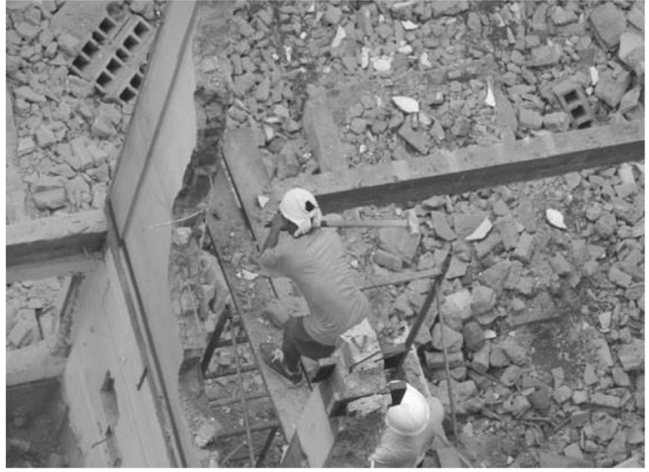

Fig. 7 Manual demolition of reinforced concrete structure in Manila

through low salaries in the informal construction sector. Expert interviews with the Philippine Department of Energy and field studies indicate no facilities for heat recovery of organic materials in the country. This was considered in phase $\mathrm{D}$ by not adding credits for heat recovery to the alternative materials, which would cause them to be assessed as too optimistic. Common EoL stages for bamboo and coconut husk panels were (1) reuse, (2) backyard incineration and (3) uncontrolled rotting, whereas reuse was considered a net benefit in phase $\mathrm{D}$, backyard incineration and uncontrolled rotting were elements in phase $\mathrm{C} 4$. There is minor transport $(\mathrm{C} 2)$, because bio-based materials reach the end-of-waste stage near the deconstruction location. Further, there is no additional waste processing after demolition (C3), prior to phase $\mathrm{C} 4$. In the scenarios, ratios of $20: 70: 10 \%$ and $40: 40: 20 \%$ were modelled.

We conducted interviews regarding recycling rates of steel and concrete in the formal and informal sectors of the Philippines, because there were no official statistics. Manual demolition of reinforced concrete was taken into account. It was further assumed that reinforcement steel was either (1) reused for different applications, (2) not recovered or (3) recovered and shipped as scrap material to facilities in neighbouring countries. Minor transport was considered for reuse near the demolition site, and major transport with an average harbour distance to China was considered for recovery and shipment outside the country $(\mathrm{C} 2)$. No recovery of steel generated no further material flows. Manual waste processing, causing only minor material inflow, was assumed for steel prior to the end-of-waste stage, for reuse as scrap metal (C3). Net benefits for reused, recovered and shipped scrap were allocated to phase D. A 20:20:60 ratio was used.

Concrete after demolition will either be (1) reused as backfill material or used in road construction or (2) disposed in landfills. No recycling of concrete was identified in the Philippines. In both cases, transport was considered (C2). Manual waste processing, causing only minor material inflow, was taken into account for reuse as backfill material, and there was no waste processing for disposal in landfills (C3). Landfilling of demolished concrete was modelled in phase $\mathrm{C} 4$. A 30:70 ratio 
was used between reuse and landfilling. The EoL for buildings at the base of the pyramid is generally a subject for further study. All scenario assumptions for phases $\mathrm{C}$ and $\mathrm{D}$ are documented in the Electronic Supplementary Material.

\section{Results}

The results below are based on the single-impact indicators GWP and CED as well as the endpoint categories Human Health, Ecosystem Quality, Climate Change and Resources of the indicator Impact2002+. More details on nonaggregated midpoint results can be found in the Electronic Supplementary Material. The results of Fig. 8 show phases
A-B-C-D, excluding phases B1 and B5-B7 as explained in Sect. 2.2.5, and with boundary conditions defined as in the base case. In the latter case, the coconut board-based house had the greatest impact reduction at $82.6 \%$. The cement-bamboo frame technology reduced the environmental impact by $74.4 \%$ and the soil-cement block technology by $35.2 \%$, compared with the conventional concrete house. The concrete technology has served as the reference for $100 \%$ impact of a typical social house. In absolute terms, this relates to a reduction of $10.3,9.3$ and $4.4 \mathrm{t} \mathrm{CO}_{2}$ eq., respectively. We emphasize that the conventional foundation and finishing such as windows, plumbing and electricity were excluded from the assessment (Sect. 2.1.2); therefore, the absolute reduction in $\mathrm{t}$ $\mathrm{CO}_{2}$ eq. provides a quantitative picture.

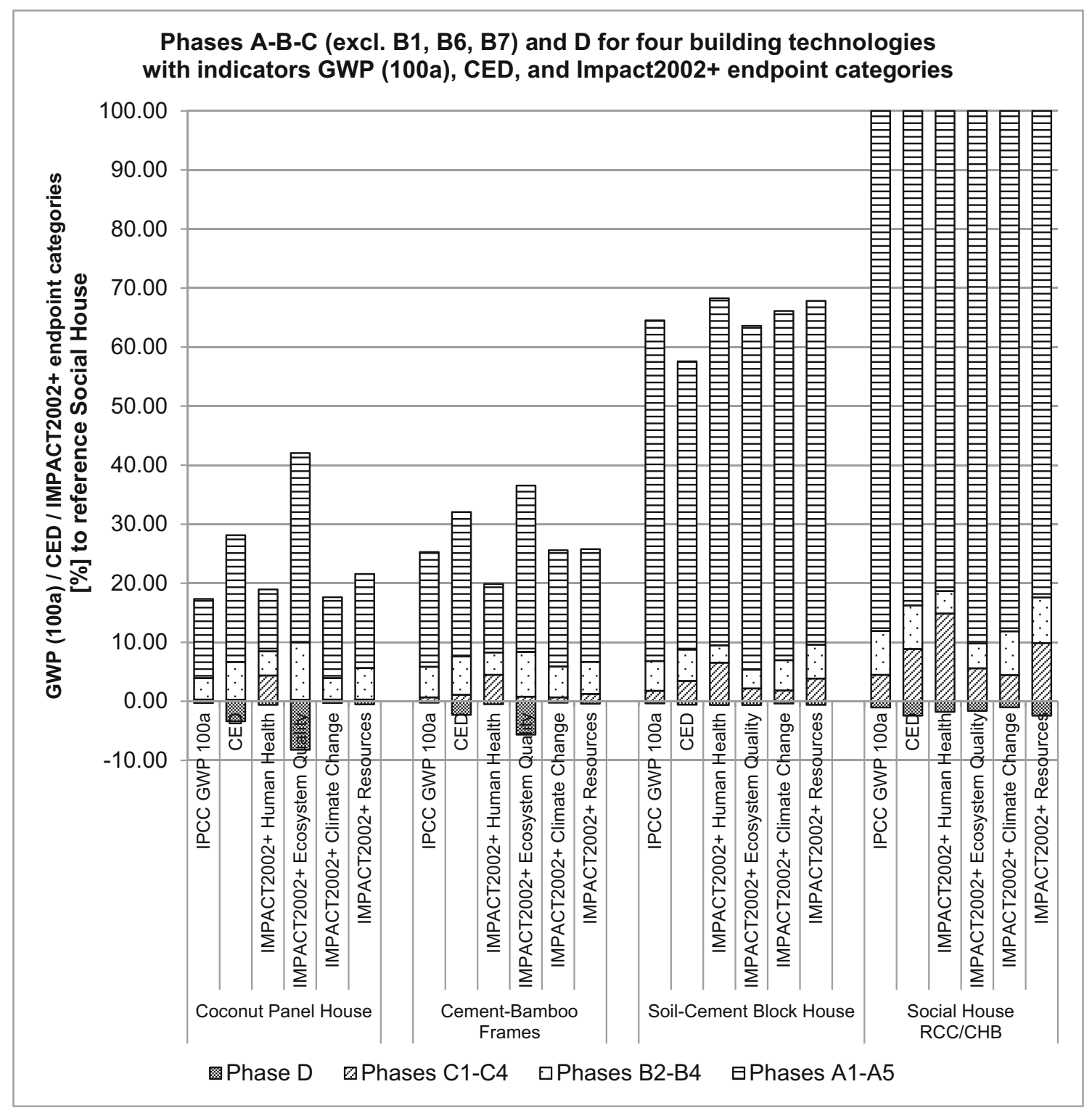

Fig. 8 Results for four building technologies in [\%] to reference houses for three indicators GWP (100a), CED, Impact2002+ endpoint categories, phases $A-B-C$ (excl. B1, B6, B7) on positive axis and phase $D$ on negative axis 
Assessing the results of the indicator GWP, the major impact is caused by modules A1-A5 with 78-90\% across the technologies. The impact of phases B2-4 contributed 7-21\% to the overall impact on the houses. Scenario results increased the contribution up to $36 \%$, depending on the maintenance frequency. For scenario results it is referred to the Electronic Supplementary Material. Given a lack of data for phases B1, B6 and B7, this topic is subject to further research and was not included in the assessment. As a result of the social housing context and the missing phases, the use phase is considerably smaller than for conventional LCAs in western countries, where the energy consumption during the use-phase alone contributes $70-90 \%$ to the overall life cycle balance (Ortiz et al. 2009; Singh et al. 2011; Abd Rashid and Yusoff 2015). The major impact of phase B was from maintaining conventional material components, both for alternative and conventional building envelopes (roof sheets and plaster finish). Research on the demolition and waste scenarios for the formal construction sector states that its relevance lies at $4-10 \%$ of the overall LCA impact (Coelho and de Brito 2012; Carpenter et al. 2013). In this assessment, the impact share of phase $C$ was lower with 1.8-4.5\%. Scenarios for the biogenic building technologies resulted in a change of less than $0.3 \%$. Module D ranges from -0.5 to $-1.6 \%$ of the overall life cycle impact per technology. The dominance of phases A can be explained since no operational energy use was included and in-country recycling of concrete or steel, biogenic carbon credits and heat recovery for organic matter was found to be not applicable for the given case. To evaluate the robustness of the trend obtained with use of the single-impact indicator GWP (100-year horizon), two further indicators were applied. The indicator CED was identified as a proxy for the commodity building material (Huijbregts et al. 2010), and the aggregated multiimpact indicator Impact2002+, containing several more single-impact indicators of EN15978 allocated to four damage categories Human Health, Ecosystem Quality, Climate Change and Resources. CED showed higher impacts for the biogenic construction methods coconut board and cementbamboo frame technology, with a difference of +8.0 and $+4.7 \%$, respectively, from GWP to CED. The soil-cement technology was evaluated $-7.1 \%$ with CED compared to GWP. Three of the four endpoint categories of Impact2002+ , Human Health, Climate Change and Resources, showed variations not exceeding 3, 6 and 4\% for coconut panel-based, cement-bamboo frames and soil-cement as displayed in Fig. 8. Higher variations were noticeable in the endpoint category Ecosystems Quality with less reduction for the bio-based technologies of $24 \%$ for coconut panels and $17 \%$ for cementbamboo frames, changing the ranking between coconut and bamboo among the four technologies. The cause for this variation was found in the midpoint category "land occupation", allocated to the endpoint Ecosystem Quality. The latter was clearly less favourable for the biogenic materials. The topic land use is picked up in Sect. 4. For more detailed results on the midpoint categories, it is referred to the Electronic Supplementary Material. A total reduction of 58,63 and $36 \%$ for coconut panel-based, cement-bamboo frames and soil-cement remained on the level of the endpoint category Ecosystem Quality. Overall, a robust, clear reduction compared to the conventional construction was confirmed across all indicators, except for land occupation. Additionally, the application of an aggregated single-score result for all endpoint categories is specified in the Electronic Supplementary Material. A high congruence between the single-impact indicators and the endpoint category results, as displayed in Fig. 8, supports the approach of displaying selected single-impact predictors for this paper to enable a clear messaging. In case of interest on specific concerns, the respective single-impact indicators are recommended to be added.

Figure 9 shows the GWP for the relevant phase A1-A5 according to its inflow categories. The conventional raw materials contribute with more than $85 \%$ to the cement-bamboo frame technology with galvanized iron roofing, cement and metallic plaster carrier of 48, 27 and 10\% contribution, respectively. For the coconut board-based house, the dominance of the metallic roof sheeting is even stronger with $70 \%$ of contribution. This noticeable impact can guide future improvement effectively. A change to concrete shingles for roofing, which would reduce the environmental impact as much as $10 \%$ for the cement-bamboo frame technology, is however not applied in the Philippines and therefore not considered in this LCA. When assessing the block-based technologies on A1-A5 level, five major inflows could be identified: the blocks, reinforcement steel, steel for the roof structure modelled as steel low alloyed, roof decking metal sheets and cement. For the RCC/CHB technology, these five inflows contributed $93 \%$ of the impact on A1-A5 level; for the SCB technology, they were related to $94.6 \%$ of impact. Figure 9 visualizes the results.

Based on studies of the supply, production and construction processes, sensitivity analyses for phases A1-A5 were formulated, as described in Sects. 2.2.2, 2.2.3, and 2.2.4, and clustered into minimum and maximum scenarios according to their influence on the overall accumulated impact. The obtained ranges showed that also in conservative cases, the alternative technologies remain reducing the environmental impact at a comparable order of magnitude, with the soil-cement blocks being most sensitive to variations. For results of the scenarios it is referred to the Electronic Supplementary Material.

The effect of the building lifespan was studied in two scenarios, keeping the RSP at 25 years. In scenario one (10 years for all alternatives, 25 years for conventional), environmental impact of the bamboo technology was $55 \%$ of a social house made of concrete, while the soil-cement block house was already 53\% exceeding the conventional solution. The comparative advantage for cement-bamboo frame was greatly 
Fig. 9 Results for four construction technologies: coconut board-based house ( $\mathrm{Coco})$, bamboo-cement frames $(B C F)$, soil-cement blocks $(S C B)$ and reinforced concrete frame with concrete hollow blocks $(R C C / C H B)$, phases A1-A5 and GWP (100a) according to inflow category

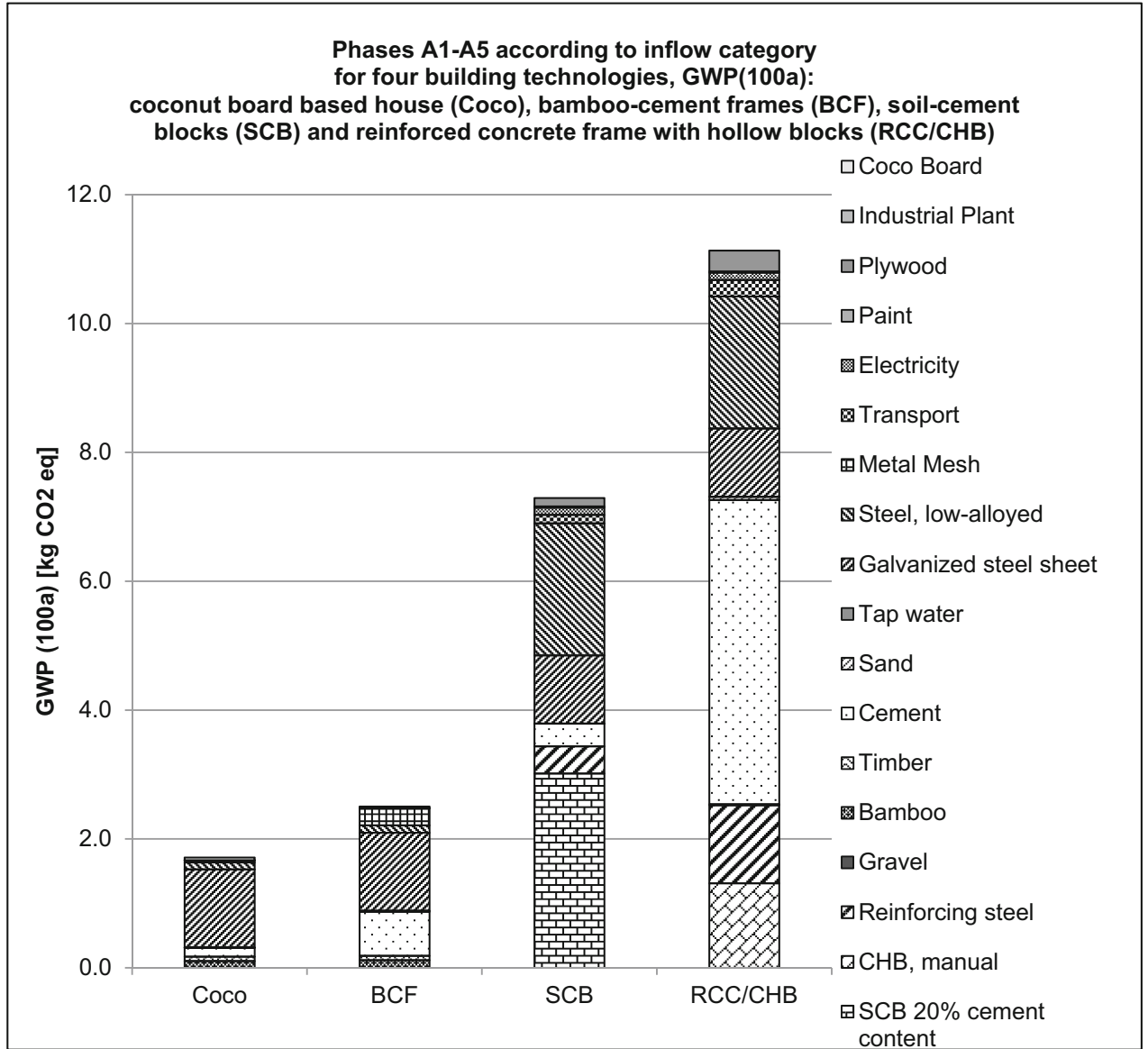

reduced in scenario two, at only $16.2 \%$ (10 years for bio-based structures, 40 years for block-based). Figure 10 shows the results for the phases A-B-C and phase D.

For further results of the scenarios of phases B and C, it is referred to the Electronic Supplementary Material.

\section{Discussion}

Below, we provide a systematic discussion of the results with two major characteristics in mind: (1) Discussion about life cycle phases, system boundaries and scenarios leading to the results and (2) relevance of life cycle thinking to social housing in the informal sector of the emerging economy.

\subsection{Life cycle phases, system boundaries and scenarios of the LCA}

The validity of the phase A results was confirmed through a correlation analysis. The transition from theoretically modelled to empirically proven data resulted in a variation of $< \pm 10 \%$. According to EN15804, the effect on the result is classified a non-significant change in the environmental performance of the products. With that, the inflows were triangulated and confirmed in their order of magnitude. The assumptions of the theoretically modelled data are therefore assessed as valid, while the updating with the empirical data enabled to lower uncertainty. The theoretical assumptions for the scenarios of phases B, C and D are addressed below.

\section{Use phases (B1-B6):}

- The LCA assumed that all houses, irrespective of their building technology, have a lifespan of 25 years. The importance of the variable service lifespans was visualized via scenarios with reduced lifespans for the alternative methods of 10, 20 and 40 years, for a fixed reference study period. It was shown that the competitive advantage is strongly reduced or even turned into a disadvantage, when the alternative technologies have a shorter lifespan. The relevance of the results is therefore not applicable to the general use of bamboo, coconut husks or soil-cement, but is limited to the advanced building methods introduced in this paper.

- In previous LCAs for buildings, it was found that the use phase of the houses is vital from a life cycle perspective (Ortiz et al. 2009; Singh et al. 2011; Abd Rashid and Yusoff 2015). User behaviour of inhabitants at the base 


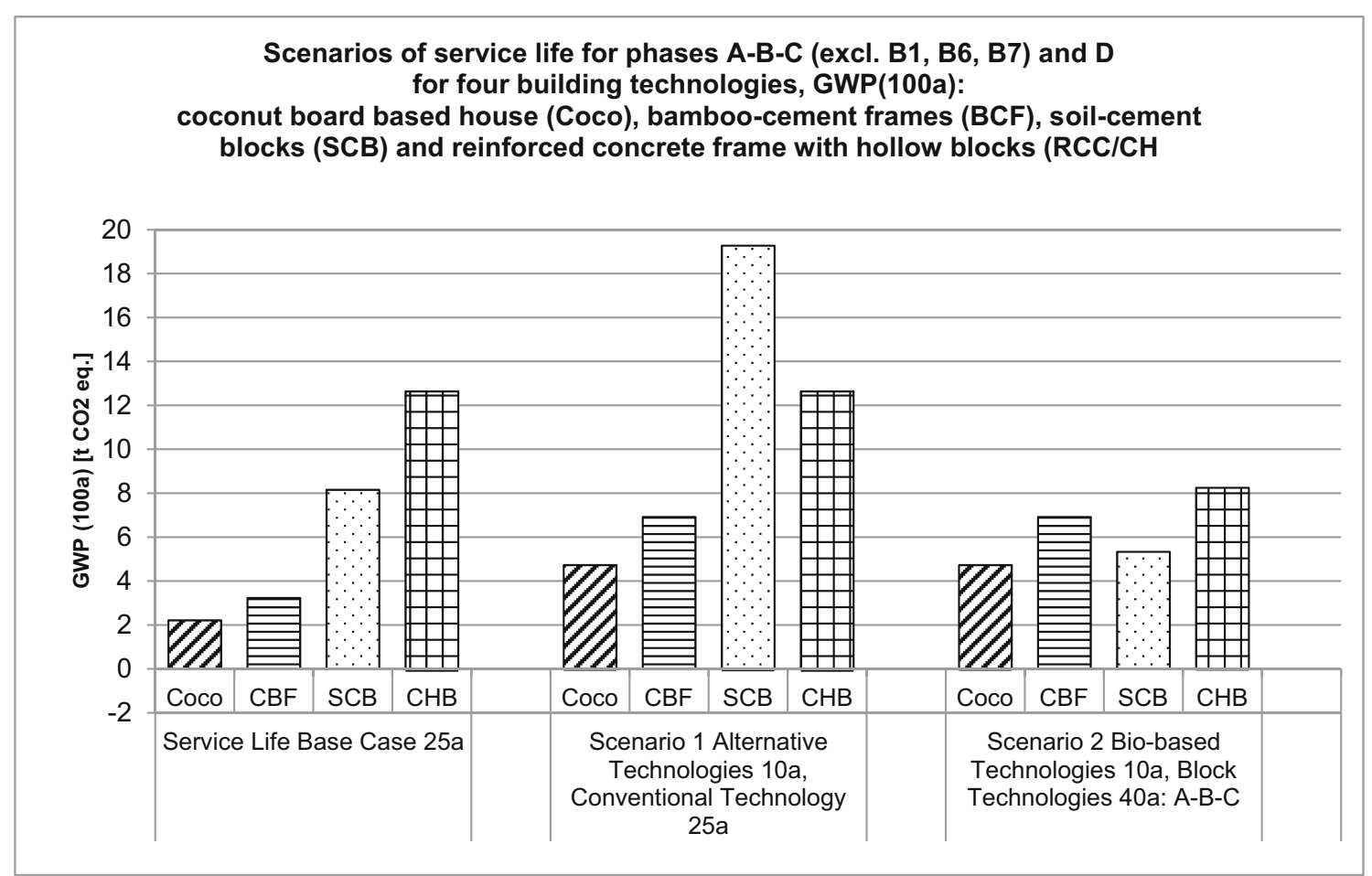

Fig. 10 Results of service life scenarios for four building technologies, GWP (100a), phases $A-B-C$ (excl. B1, B6, B7) on positive axis and phase D on negative axis

of the pyramid has never been systematically assessed nor captured in LCA. The hypothesis that a building technology combined with a climate-adjusted design can change the behaviour of inhabitants lacks proof for low-income groups. Possibly, the user behaviour is not influenced by the type of building envelope or indoor comfort, but rather limited by poverty. The reduction potential of A1-A5 as presented herein attains greater relative importance in this case. It is conservative to assume that there is no competitive advantage of the alternative building methods and that phase B can be excluded. Or, if the indoor comfort of houses affects the behaviour of energy-consuming appliances (phase B6), it poses an interesting research question that needs more in-depth study.

End-of-life (C1-C4) and beyond life cycle (D): A study of the characteristics of the informal sector in the Philippines and recent scientific debates guided the decisions taken for phases $\mathrm{C}$ and $\mathrm{D}$. These are described in the following:

- The use of organic raw materials in long-lasting products raises the question of biogenic carbon storage, which has become a frequent topic in recent scientific publications (Guest et al. 2013; Levasseur et al. 2013; Pawelzik et al. 2013; Jørgensen et al. 2014). In essence, credits are addressed for a delayed release of carbon into the atmosphere in phase D. Although there is common sense about determining short-term and long-term emissions distinctly, there is no consensus on how to weigh such emissions (Hellweg and Frischknecht 2004). In a recent scientific investigation, it was reemphasized that no adoption of "optional" carbon storage, as mentioned in EC JRC-IES (2010), is recommended (Vogtländer et al. 2013). The IPCC GWP indicator removed consideration of biogenic $\mathrm{CO}_{2}$, given the argument that emissions will re-enter the atmosphere sooner or later (Althaus et al. 2010) and that crediting is not in line with IPCC (2014) global mass balance and provisions of the ISO International Organization for Standardization (2006), based on precaution. Instead of biogenic carbon credits, Vogtländer et al. (2013) suggested careful modelling of the EoL, including credits from heat recovery and substitution.

- Nevertheless, in the Philippines, as with many other emerging economies, the technological advances available in Western economies do not exist. There were no local facilities for industrial-scale heat recovery or recycling in our reference year, with a small share of metals being recycled outside of the country. The LCA models were chosen to be conservative by not considering potential benefits beyond the building life cycle.

- Vogtländer et al. (2013) suggested that extra carbon sequestration in additional global forest areas is considered by integrating land-use changes. It is further recommended to allocate credits to an entire sector, not just one specific product. The assumption of land-use changes is only 
justified when an increase in product application is foreseen within a stable industrial setting. Because development of a bamboo-based industry in the Philippines is connected to very uncertain variables, our LCA did assess land-use change in unlikely in near future.

- In EN16485, carbon neutrality is discussed for biogenic products modelled in LCA. We argue that bamboo has special growth characteristics, which justify the carbon neutrality assumption: In the Philippines, bamboo grows along river banks and sloping land, not attractive for agricultural use or land development. Plantations hardly exist. The Philippine Government noted this potential and promotes it for erosion control on unfertile or risky lands. Land competition and loss of biodiversity are therefore only scenarios on very large scale. Respective yields of natural stands have been taken into account for this article. Bamboo clumps have a limited natural size and culms decay after few years to allow reproduction. Therefore, culms can be harvested without reduction of existing stocks, providing farmers annual reoccurring income (International Network for Bamboo and Rattan 2011).

- For scale-up scenarios indicating a future change in consumer patterns, we recommend in-depth studies on the effects of biodiversity, scarcity and land-use changes. The ongoing decay of a rich biodiversity in Southeast Asia requires careful consideration of any large-scale system change (Sodhi et al. 2010; Webb et al. 2010). Research has shown that the commonly used indicators in LCA that address such topics are not sufficiently comprehensive and systematic (Curran et al. 2011; Michelsen et al. 2012; Finkbeiner et al. 2014). Although improved integration into LCA is becoming a focus in the field (e.g., Koellner et al. 2012; De Souza et al. 2013), we recognize the current shortcomings regarding these aspects and the existence of more elaborate methods outside of LCA (Lindner et al. 2012; Liptow 2014). The lack of such data is not unique to this paper and has been acknowledged as a major gap in LCA today (Finkbeiner et al. 2014). It is suggested to monitor development in this field and update present LCA once an expert approach is validated and acknowledged. These indicators become more crucial when the analysed alternative technologies replace current practices at a relevant scale. We recommend following the cautious principles toward resource use in large quantities and the guidance of experts in the sector.

\subsection{Relevance of life cycle thinking for the social housing sector in emerging economies}

The impacts of the social housing sector in emerging economies are not yet assessed by life cycle thinking. This sector constitutes a substantial share of national construction activities in emerging economies. Its rapid growth recommends that it be included in environmental impact assessments of the global construction sector.

Using the example of the Philippines, the present case study evaluated the environmental performance of a typical building for low-income groups, using selected alternative construction methods. Large-scale change of the national building stock in the country has not been examined in detail. The following characteristics describe the potential and limitations of the case study and underline the relevance of further research into life cycle thinking as guidance for sectorial assessment.

- The assessed alternative construction technologies meet urban rules and regulations. As such, a basis is provided to address a predominantly urban housing need. The technologies' technical and economical suitability was proven by Base Builds (2015). In comparison to traditional temporary shelters made with the same raw material, enhanced durability or service life was the main differentiator. Protection from sun, moisture and insects induced decay. Resistance against fire, wind and earthquakes are criteria that support system change at larger scale. Because durability of buildings is a key consideration in life cycle thinking, validity of the present research is limited to elaborate alternative building methods as the ones selected. Results do not apply generally, when the said raw materials are used in less elaborate ways.

- A limitation of the alternative technologies is their suitability to low-rise structures of one to three stories only. This allows treatment of only a share of the national housing need. Further technical research needs to prove fire, wind and earthquake resistance and acoustic performance for multi-story applications, irrespective of whether round or laminated bamboo is used.

- National spread of the alternative technologies depends on building sustainable supply chains, policy advocacy and multi-stakeholder involvement of governments, academia, the private sector, NGOs and informal settlers. The case study advocates this.

- Overall, there is an intriguing correlation at global scale between rapidly growing urban centres and the availability of alternative raw materials such as bamboo. Therefore, there is potential to transfer the case study to many other countries with pressing housing needs. With $40 \%$ of the urban population in both the Philippines and the general Asia Pacific region being low-income groups in need of housing (UN Habitat Philippines 2009; UN-ESCAP and UN-Habitat 2011), the advocacy of life cycle thinking is important for achieving a more sustainable, inclusive urban development at city, country and regional scale. 


\section{Conclusions and recommendations}

The general objective of the present research was to compare the environmental impact of typical conventional houses of low-income groups in the Philippines with selected alternative construction technologies. An LCA showed that the alternatives cement-bamboo frames, coconut board-based houses and soil-cement blocks have substantial potential to reduce environmental performance. These results must be seen in light of promising results in technical, economic, social and governance dimensions, because factors such as lifespan are of critical importance to obtained performance and legal approval is a critical requirement for actual implementation. The environmental impact of the building sector remains of global importance. IPCC scenarios show that the non-annex countries in Southeast Asia have the greatest predictions of emissions growth in the sector, followed by Latin America and Africa (IPCC 2014). In the emissions summary for the Philippines, an annual national production of 126,900 Mt. $\mathrm{CO}_{2}$ equivalent, without land-use and forestry changes, was identified for the base year 2000. An annual increase of 3.9\% was indicated from 1994 through 2000 (UN Climate Change Secretariat 2000). As an approximation for the Philippine building sector and building use, an average global contribution of one third assigns the substantial amount of 41,200 Mt. $\mathrm{CO}_{2}$ equivalent to buildings in the country. In-depth assessments of the sector contribution are recommended to consider country-specific building situations and their development. Because the building sector has the greatest low-cost GHG mitigation potential, irrespective of world region (UNEP SBCI 2009), measures to reduce its impact have strong national relevance. The present study showed reduction potentials not only in advanced building stock but also in the social housing subsector. A strong focus is recommended on this subsector, given its current share and especially its anticipated continuous increasing impact. Its relevance is underlined by more than 25 million people living in slums today who have an urgent need for more adequate housing, and an urban growth rate $>2 \%$ that mainly affects lower income levels. In 2015, the Philippines submitted targets for its Intended Nationally Determined Contribution to the United Nations. By the year 2030, a $\mathrm{CO}_{2}$ reduction of $70 \%$ is intended. Such ambitious targets can only be achieved by addressing the building sector. The LCA presented herein adds quantitative ecological arguments that can guide decision makers (Finkbeiner et al. 2014) for a rapidly growing sector of emerging economies. Further studies of alternative building technologies are needed, with attention to large national and globalscale applications. In-depth assessments of large-scale application effects on biodiversity and land-use change are recommended. Further, it is worthwhile to reduce data uncertainty for phases B, C and D in the social housing sector, with a prominent role for the use phase of houses. Use-phase consumption can rise with volatility with an increase of lowincome groups in urban areas and a substantial number of people transitioning from the lowest to greater-consuming upper-lower or lower-middle income levels. We recommend study of the indoor thermal environment in social housing, its impact on user behaviour and resulting energy consumption. Future life cycle research can directly address social impacts (e.g., as in Caraty et al. 2005; Petti et al. 2009; Dewulf et al. 2013; Hosseinijou et al. 2014; Iofrida et al. 2014), as an alternative to using separate one-dimensional environmental and social indicators and combining them in a multi-criteria decision-making process. Inclusive local supply chains, skills for processing raw materials into operating construction systems and a focus on customer needs in the design of housing concepts are characteristics that can be considerations in Social LCA. Integration of LCA in multi-criteria decisionmaking is identified as a relevant activity for future development (Singh et al. 2011). Multi-stakeholder dialogues such as in Frischknecht et al. (2015) can support such integration and systematic use of life cycle thinking. Such dialogues must become more inclusive, adding stakeholders and decision makers from key sectors in emerging countries, in order for the presented concepts to gain relevance in fast-growing sectors of their economies.

Acknowledgements The research presented in this paper feeds into a larger program on sustainable and resilient low-cost housing initiated by the Hilti Foundation (http://www.hiltifoundation.org/en/). It started as a partnership with the United Nations Economic and Social Commission for Asia and the Pacific (UN ESCAP) and the Homeless People's Federation of the Philippines (HPFPI) and evolved into the establishment of the initiative Base (http://www.base-builds.com/). Acknowledgement is given to Base, who has contributed empiric data from their bamboo construction projects, and the HPFPI, who has contributed to concrete and soil-cement inventories. Furthermore, we acknowledge Chalmers Area of Advance Built Environment profile "Responsible Use of Resources" for the support of research on social housing in emerging economies.

Open Access This article is distributed under the terms of the Creative Commons Attribution 4.0 International License (http:// creativecommons.org/licenses/by/4.0/), which permits unrestricted use, distribution, and reproduction in any medium, provided you give appropriate credit to the original author(s) and the source, provide a link to the Creative Commons license, and indicate if changes were made.

\section{References}

Abd Rashid AF, Yusoff S (2015) A review of life cycle assessment method for building industry. Renew Sust Energ Rev 45:244-248

Abd Rashid AF, Yusoff S, Mahat N (2013) A review of the application of LCA for sustainable buildings in Asia. Adv Mater Res 724-725: 1597-1601

Althaus H-J, Bauer C, Doka G et al (2010) Implementation of life cycle impact assessment methods. Final report ecoinvent v2.2 No. 3, Swiss centre for life cycle inventories, Dübendorf 
ASEP (2010) National Structural Code of the Philippines, volume 1buildings, towers and other vertical structures, 6th edn. Association of Structural Engineers of the Philippines, Quezon City

ASEP (2014) Post disaster damage assessment of Bohol EarthquakeWhy houses fell down. Association of Structural Engineers of the Philippines, Quezon City

Barile ER (2007) Monograph on production and utilization of Philippine bamboos. Forest Products Research and Development Institute, Los Banos

Base Builds (2015) Sustainable and resilient housing for low income groups in the tropics. www.base-builds.com

Boeger T, Bianchi S, Salzer C, Pichelin F (2017) Binderless boards made of milled coconut husk: an analysis of the technical feasibility and process restraints. Biel, unpublished work

Cabeza LF, Rincón L, Vilariño V et al (2014) Life cycle assessment (LCA) and life cycle energy analysis (LCEA) of buildings and the building sector: a review. Renew Sust Energ Rev 29:394-416

Caraty M, Chanteau J, Thomas J, Revéret J (2005) How to assess the social value of a steel product? 4th Soc Sem, pp 63-69, Proceedings of the 4th International Seminar in Social Social Life Cycle Assessment, 19th-21st Nov 2014, Montpellier, online: http:// social-lca.cirad.fr/content/download/4264/32008/version/1/file/ Thema+2+-+Sess2-4+Caraty+et+al.+2014_4thSocSem_SLCA Montpellier.pdf

Carpenter A, Jambeck JR, Gardner K, Weitz K (2013) Life cycle assessment of end-of-life management options for construction and demolition debris. J Ind Ecol 17:396-406

CIB (2014) W110 - informal settlements and affordable housing. In: Proceedings of the Architecture Otherwhere Congress, International Council for Research and Innovation in Building and Construction, Publication 401, Working Group CIB W110, Aug 3-7 2014, Durban, online: http://www.irbnet.de/daten/iconda/CIB DC27923.pdf

Cleuren HM, Henkemans AB (2003) Development of the bamboo sector in Ecuador: harnessing the potential of Guadua angustifolia. J Bamboo Ratt 2:179-188

Coelho A, de Brito J (2012) Influence of construction and demolition waste management on the environmental impact of buildings. Waste Manag 32:532-541

Curran M, De Baan L, De Schryver AM et al (2011) Toward meaningful end points of biodiversity in life cycle assessment. Environ Sci Technol 45:70-79

De Souza DM, Flynn DFB, Declerck F et al (2013) Land use impacts on biodiversity in LCA: proposal of characterization factors based on functional diversity. Int J Life Cycle Assess 18:1231-1242

Department of Trade and Industry Philippines (2013) DTI. http://www. dti.gov.ph/

Dewulf J, Mancini L, Blengini GA et al (2013) Social issues in classical and social LCA: from identification of overlaps to an integrated. framework. $4^{\text {th }}$ Soc Sem, pp 27-33

EC JRC-IES (2010) International Reference Life Cycle Data System (ILCD) handbook: specific guide for Life Cycle Inventory data sets. EUR 24709 EN

ecoinvent Centre (2014) Life cycle inventory database. http://www. ecoinvent.org/

EN 15804:2012+A1:2013 (2015) Sustainability of construction worksenvironmental product declarations - Core rules for the product category of construction projects

EN15978 (2011) EN 15978:2011 Sustainability of construction worksassessment of environmental performance of buildings - calculation method

Finkbeiner M, Inaba A, Tan R et al (2006) The New International Standards for Life Cycle Assessment: ISO 14040 and ISO 14044. Int J Life Cycle Assess 11:80-85

Finkbeiner M, Ackermann R, Bach V et al (2014) Background and future prospects in life cycle assessment. In: Background and future prospects in life cycle assessment. Springer, p 271. doi:10.1007/ 978-94-017-8697-3

FPRDI (2002) Utilization, collection and trade of tropical non-wood forest products in the Philippines. Forest Products Research and Development Institute, Los Banos

Frischknecht R, Wyss F, Knöpfel SB, Stolz P (2015) Life cycle assessment in the building sector: analytical tools, environmental information and labels. Int J Life Cycle Assess 20:421-425

Guest G, Bright RM, Cherubini F, Strømman AH (2013) Consistent quantification of climate impacts due to biogenic carbon storage across a range of bio-product systems. Environ Impact Assess Rev 43:21-30

Habitech (2015) Interlocking Soil-Cement Blocks. http://www.habitech. ait.asia/

Heeren N, Hellweg S (2014) Influence of construction material choice and design parameters on greenhouse gas emissions of buildings. WSB14 13786:9-16

Hellweg S, Frischknecht R (2004) Evaluation of long-term impacts in LCA. Int J Life Cycle Assess 9:339-341

Homeless People's Federation of the Philippines (2013) Community empowerment through savings. http://www.achr.net/index.php. Accessed 30 Nov 2015

Hosseinijou S, Mansour S, Shirazi M (2014) Social life cycle assessment for material selection: a case study of building materials. Int J Life Cycle Assess 19:620-645

Huijbregts MAJ, Hellweg S, Frischknecht R et al (2010) Cumulative energy demand as predictor for the environmental burden of commodity production. Environ Sci Technol 44:2189-2196

SDSN (2013) Why the world needs an urban sustainable development goal. pp 1-6, United Nations Sustainable Development Solutions Network, New York. http://www.unsdsn.org

International Network for Bamboo and Rattan (2011) The climate challenge and bamboo: mitigation and adaptation, International Network for Bamboo and Rattan, Working Paper No.65, Beijing

Iofrida N, De Luca AI, Strano A et al (2014) Social life cycle assessment in a constructivist realism perspective: a methodological proposal. pp 44-50, Proceedings of the 4th International Seminar on Social Life Cycle Assessment, 19th-21st Nov 2014, Montpellier, online: http://social-lca.cirad.fr/content/download/4261/31996/version/1/ file/Thema+2+-+Sess2-1+Iofrida+et+al.+2014_4thSocSem SLCA_Montpellier.pdf

IPCC (2014) Climate Change 2014: Synthesis report. Contribution of working groups I, II and III to the fifth assessment report of the intergovernmental panel on climate change. IPCC, Geneva

ISO International Organization for Standardization (2006) ISO 14044 environmental management, life cycle assessment, requirements and guidelines. Geneva

Jolliet O, Margni M, Charles R et al (2003) IMPACT 2002+: a new life cycle impact assessment methodology. Int J Life Cycle Assess 8: 324-330

Jørgensen SV, Cherubini F, Michelsen O (2014) Biogenic CO2 fluxes, changes in surface albedo and biodiversity impacts from establishment of a miscanthus plantation. J Environ Manag 146:346-354

Keijsers E, Snijder M, Oever M van den, et al. (2006) Coconut husk based building \& packaging materials. Final Report of Project CFC/FIGHF/11, Wageningen

Khasreen MM, Banfill PFG, Menzies GF (2009) Life-cycle assessment and the environmental impact of buildings: a review. Sustainability 1:674-701

Koellner T, Baan L, Beck T et al (2012) Principles for life cycle inventories of land use on a global scale. Int J Life Cycle Assess:1203-1215

Levasseur A, Lesage P, Margni M, Samson R (2013) Biogenic carbon and temporary storage addressed with dynamic life cycle assessment. J Ind Ecol 17:117-128

Lindner JP, Beck T, Schwarz S et al (2012) Proposal of a unified biodiversity impact assessment method. Ecobalance 5 
Liptow C (2014) Environmental assessment of emerging routes to biomass based chemicals. Chalmers University of Technology, Gothenburg

Michelsen O, Cherubini F, Strømman AH (2012) Impact assessment of biodiversity and carbon pools from land use and land use changes in life cycle assessment, exemplified with forestry operations in Norway. J Ind Ecol 16:231-242

NHA (2015) National Housing Authority of the Philippines. http://www. nha.gov.ph

NSO (2013) National Statistics Office, Republic of the Philippines. https://psa.gov.ph/

Ortiz O, Castells F, Sonnemann G (2009) Sustainability in the construction industry: a review of recent developments based on LCA. Constr Build Mater 23:28-39

Paudel SK, Lobovikov M (2003) Bamboo housing: market potential for low-income groups. J Bamboo Ratt 2:381-396

Pawelzik P, Carus M, Hotchkiss J et al (2013) Critical aspects in the life cycle assessment (LCA) of bio-based materials - reviewing methodologies and deriving recommendations. Resour Conserv Recycl 73:211-228

Petti L, Maria C, Ugaya L, Di Cesare S (2009) Systematic review of social-life cycle assessment (S-LCA) case studies. pp 34-41

Philippine Coconut Authority (2012) Philippine Coconut Authority. http://www.pca.da.gov.ph/

PRé Consultants (2015) SimaPro software version 8.1.0, sustainability consulting. https://www.pre-sustainability.com

Rasoolimanesh SM, Badarulzaman N, Jaafar M (2011) Achievement to sustainable urban development using City Development Strategies (CDS): a comparison between cities alliance and the World Bank definitions. J Sustain Dev. doi:10.5539/jsd.v4n5p151

Rebitzer G, Ekvall T, Frischknecht R et al (2004) Life cycle assessment part 1: framework, goal and scope definition, inventory analysis, and applications. Environ Int 30:701-720

Salzer C, Wallbaum H, Lopez LF, Kouyoumji JL (2016) Sustainability of social housing in Asia: a holistic multi-perspective development process for bamboo-based construction in the Philippines. doi:10. 3390/su8020151

Salzer C, Wallbaum H, Alipon M, Lopez LF (2017) Determining material suitability for low-rise housing in the Philippines: physical and mechanical properties of the bamboo species Bambusa blumeana, unpublished work

Sandin G, Peters GM, Svanström M (2014) Life cycle assessment of construction materials: the influence of assumptions in end-of-life modelling. Int J Life Cycle Assess 19:723-731

Singh A, Berghorn G, Joshi S, Syal M (2011) Review of life-cycle assessment applications in building construction. J Archit Eng 17:15-23

Snijder M, Kejisers E, VanDenOever M, VanDam J (2005) Coir based building and packaging materials - final report of project $\mathrm{CFC} /$ FIGHF/11

Sodhi NS, Posa MRC, Lee TM et al (2010) The state and conservation of Southeast Asian biodiversity. Biodivers Conserv 19:317-328

TenHave C, Willemsen E, Zom L et al (2010) Sustainability analysis of coir board compared to medium density fibreboard and bamboo mat board, Student Thesis, Wageningen University, Wageningen

UN Climate Change Secretariat (2000) Emissions summary for Philippines, GHG Profiles Non Annex I, United Nations Climate Change Secretariat, Framework Convention on Climate Change, Bonn, online: http://di.unfccc.int/ghg_profile_non_annex 1

UN Habitat (2012) Going green. A handbook of sustainable housing practices in developing countries. United Nations Human Settlements Programme; United Nations Economic and Social Commission for Asia and the Pacific, Nairobi

UN Habitat Philippines (2009) Country programme document 2008-2009 Philippines. United Nations Human Settlements Programme, Nairobi

UNEP SBCI (2009) Buildings and climate change: summary for decision-makers. United Nations Environment Programme Sustainable Buildings and Climate Initative, Paris

UN-ESCAP, UN-Habitat (2011) The state of Asian cities 2010/2011. United Nations Human Settlements Programme; United Nations Economic and Social Commission for Asia and the Pacific, Bangkok

Vogtländer JG, Velden NM, Lugt P (2013) Carbon sequestration in LCA, a proposal for a new approach based on the global carbon cycle; cases on wood and on bamboo. Int J Life Cycle Assess 19:13-23

Webb CO, Slik JWF, Triono T (2010) Biodiversity inventory and informatics in Southeast Asia. Biodivers Conserv 19:955-972

Zah R, Hischier R (2004) Life cycle inventories for detergents. www. ecoinvent.ch 